OPEN ACCESS

Edited by:

James J. Cai,

Texas A\&M University, United States

Reviewed by:

Agnieszka Barbara Najda,

University of Life Sciences in Lublin,

Poland

Grant Brown,

University of Toronto, Canada

*Correspondence:

Jean-Pascal Capp

capp@insa-toulouse.fr

Specialty section:

This article was submitted to Evolutionary and Population Genetics,

a section of the journal

Frontiers in Genetics

Received: 10 September 2018

Accepted: 03 May 2019

Published: 21 May 2019

Citation:

Liu J, François J-M and Capp J-P

(2019) Gene Expression Noise

Produces Cell-to-Cell Heterogeneity

in Eukaryotic Homologous

Recombination Rate.

Front. Genet. 10:475

doi: 10.3389/fgene.2019.00475

\section{Gene Expression Noise Produces Cell-to-Cell Heterogeneity in Eukaryotic Homologous Recombination Rate}

\author{
Jian Liu, Jean-Marie François and Jean-Pascal Capp* \\ Laboratoire d'Ingénierie des Systèmes Biologiques et des Procédés, Institut National des Sciences Appliquées de Toulouse, \\ UMR CNRS 5504, UMR INRA 792, Université de Toulouse, Toulouse, France
}

Variation in gene expression among genetically identical individual cells (called gene expression noise) directly contributes to phenotypic diversity. Whether such variation can impact genome stability and lead to variation in genotype remains poorly explored. We addressed this question by investigating whether noise in the expression of genes affecting homologous recombination (HR) activity either directly (RAD52) or indirectly (RAD27) confers cell-to-cell heterogeneity in HR rate in Saccharomyces cerevisiae. Using cell sorting to isolate subpopulations with various expression levels, we show that spontaneous HR rate is highly heterogeneous from cell-to-cell in clonal populations depending on the cellular amount of proteins affecting HR activity. Phleomycin-induced $\mathrm{HR}$ is even more heterogeneous, showing that RAD27 expression variation strongly affects the rate of recombination from cell-to-cell. Strong variations in HR rate between subpopulations are not correlated to strong changes in cell cycle stage. Moreover, this heterogeneity occurs even when simultaneously sorting cells at equal expression level of another gene involved in DNA damage response $(B M H 1)$ that is upregulated by DNA damage, showing that the initiating DNA damage is not responsible for the observed heterogeneity in HR rate. Thus gene expression noise seems mainly responsible for this phenomenon. Finally, HR rate non-linearly scales with Rad27 levels showing that total amount of HR cannot be explained solely by the time- or population-averaged Rad27 expression. Altogether, our data reveal interplay between heterogeneity at the gene expression and genetic levels in the production of phenotypic diversity with evolutionary consequences from microbial to cancer cell populations.

Keywords: stochastic gene expression, recombination, Saccharomyces cerevisiae, yeast, single-cell analysis, rate of evolution

\section{INTRODUCTION}

Expression variations of genes linked to DNA repair and recombination often affect genome stability (Stirling et al., 2011; Ang et al., 2016; Duffy et al., 2016). Whether variable expression levels from cell-to-cell due to gene expression noise could affect homologous recombination (HR) rate and thus genome stability in different subpopulations of clonal populations has not been addressed yet. Noise in gene expression is the variation in the expression level of a gene under 
constant environmental conditions (Raser and O'Shea, 2005). Downstream effects of noise can have profound phenotypic consequences, drastically affecting gene expression (Blake et al., 2003). This variation in gene expression among genetically identical individual cells could be an advantage in that it would allow heterogeneous phenotypes even in clonal populations, enabling a population of organisms to contain subpopulations with different behaviors and favoring emergence of adapted cells upon environment fluctuation and/or stress conditions (Fraser and Kaern, 2009). Interestingly, genes involved in environmental stress response and metabolism have higher levels of expression noise compared to genes of other biological function in yeast and bacteria (Bar-Even et al., 2006; Newman et al., 2006; Silander et al., 2012). Nevertheless, noise in the expression of precise genes has rarely been shown to be the source of advantageous phenotypic heterogeneity (bet-hedging strategy) and few studies have investigated fitness effects of noise (Viney and Reece, 2013; Liu et al., 2016).

In Sacharomyces cerevisiae expression noise in stress resistance genes confers a benefit in constant stressful conditions because it generates, in the absence of stress, a phenotypic diversity that makes the presence of pre-adapted cells more probable (Blake et al., 2006; Smith et al., 2007; Liu et al., 2015). In addition, recent works showed that heterogeneity in resistance phenotypes due to noise clearly promotes evolvability and shapes mutational effects, partly by modulating the adaptive value of beneficial mutations (Bodi et al., 2017). Also, noise in the expression of genes involved in the DNA replication, repair and recombination processes could directly produce cell-to-cell heterogeneity in the rate of mutation and/or recombination that would also have consequences in terms of evolvability of the population in selective environments (Capp, 2010). Such heterogeneity in mutation rate were recently theoretically studied at various evolutionary timescales (Alexander et al., 2017).

Impact of noise in gene expression on cellular response to DNA damage was investigated in Escherichia coli by monitoring the impact of expression variation of the Ada protein in response to DNA alkylation damage (Uphoff et al., 2016). These authors showed that variable induction times of the damage response were observed depending on the initial expression level of Ada, with cells that do not respond for generations because no Ada proteins are initially expressed. This creates a subpopulation of cells with an accumulation of foci of the DNA mismatch recognition protein MutS used as a marker for labeling nascent mutations (Uphoff et al., 2016), showing heterogeneity in the mutation rate at the single-cell level. The conclusion of the study highlighted that non-genetic variation in protein abundances thus leads to genetic heterogeneity. Nevertheless, this measurement remains an indirect evaluation of the genetic heterogeneity through the detection of a mismatches biosensor. Moreover neither the genetic consequences of noise in expression of DNA repair genes on a genomic substrate, nor its subsequent phenotypic consequences, were analyzed. Finally investigating similar phenomena in eukaryotes is motivated by their higher number of different proteins and more complex pathways involved in the DNA replication, repair and recombination processes that diversify and multiply the possible sources of cell-to-cell variation in mutation and recombination rate.

For simplicity, HR can be defined as the repair of DNA lesions based on homologous sequences (Symington et al., 2014). It underlies a number of important DNA processes that act to both stabilize [e.g., repair of DNA double-strand breaks (DSBs)] and diversify (generation of crossover during meiosis) a genome. Meiotic HR rate for instance has revealed considerable inter-individual differences (Dumont et al., 2009) or extensive variations along chromosomes (Kauppi et al., 2004). But technical limitations only allowed studies on whole cell populations, providing an averaged view of this process. Only recent studies of meiotic HR have revealed the diversity in crossover frequency in single sperm cells (Lu et al., 2012; Wang et al., 2012) or oocytes (Hou et al., 2013). Spontaneous mitotic HR rate also varies along chromosomes, with for instance elevated recombination rates in transcriptionally active DNA (Thomas and Rothstein, 1989), but analysis of cell-to-cell heterogeneity in mitotic HR rate in clonal cell populations is still lacking.

Mitotic HR is entirely conservative when it occurs following DNA replication where a sister chromatid is available as a template. However, HR acting on DSB can produce genome instability, especially when utilizing sequences on a homologous chromosome that can lead to crossovers and potential loss of heterozygosity, or when occurring between dispersed repeated DNA. Indeed interrepeat recombination can cause deletions, duplications, inversions or translocations, depending on the configuration and orientation of the repeat units. These non-conservative events are especially studied in this work because there are of major importance for evolution.

Homologous recombination pathways are particularly well-documented in S. cerevisiae (Paques and Haber, 1999; Symington et al., 2014). A diversity of mechanisms can modify HR activity, either indirectly by increasing the generation of DNA lesions, or directly by blocking the completion of HR and/or altering the kinetics of genetic recombination and the assembly/disassembly of the HR protein complexes (Alvaro et al., 2007). Each class of mechanism is respectively well-represented in $S$. cerevisiae by the absence of the RAD27 and RAD52 genes. On the one hand, Rad52 is involved in multiple pathways of repairing DSB (Symington, 2002). It binds single-stranded DNA to stimulate DNA annealing and to enhance Rad51-catalyzed strand invasion during the HR process called synthesis-dependent strand annealing (New et al., 1998; Song and Sung, 2000). It is also involved in Rad51-independent pathways used to repair DSB such as single-strand annealing (SSA; Symington et al., 2014). SSA is stimulated if the DSB lies in a unique sequence between two repeated sequences and can lead to the repeat contraction or expansion. The various roles of Rad52 explain the highly defective mitotic recombination in rad52 $S$. cerevisiae mutants (Dornfeld and Livingston, 1992; Rattray and Symington, 1994). On the other hand, the RAD27 gene of $S$. cerevisiae encodes a $5^{\prime}-3^{\prime}$ flap exo/endonuclease, which is a functional homolog of mammalian FEN1/DNaseIV that plays an important role during DNA replication for Okazaki fragment maturation (Balakrishnan and Bambara, 2013). It cleaves the unannealed 5' "flap" structure 
containing the primer that appears in $5^{\prime}$ of the previous Okazaki fragment after synthesis of the next one (Zheng and Shen, 2011). The absence of $R A D 27$ generates an accumulation of $5^{\prime}$ flap structures that can be resolved by the Rad52 dependent-HR pathway (Debrauwere et al., 2001). S. cerevisiae rad27 $\Delta$ mutants accumulate single- and DSB (Tishkoff et al., 1997) and display a broad array of defects in genome stability including an increased spontaneous recombination (Johnson et al., 1995; Sommers et al., 1995; Tishkoff et al., 1997). In contrast, recent data showed that overexpressing $\operatorname{Rad} 27$ in yeast coincided with increased phosphorylation of histone $\mathrm{H} 2 \mathrm{~A}$ at serine 129 , a mitosis entry checkpoint 1 (Mec1) target and marker for single-strand DNA gaps and/or DSB (Becker et al., 2018). It is therefore probable that $R A D 27$ overexpression interferes with normal replication progression and causes checkpoint activation. In agreement with the presence of DNA damage markers, reduced viability upon deletion of RAD52 was also observed. The requirement for $R A D 52$ to tolerate $R A D 27$ overexpression suggests that overexpression may lead to replication stress and eventually DSBs that require $\mathrm{HR}$ for efficient repair, as $\operatorname{rad} 27 \Delta$ deletion does.

Here, we choose to use a $S$. cerevisiae strain containing a HR substrate that allows measuring the rate of non-conservative interrepeat recombination events and to sort subpopulations depending on the native expression level of RAD27 and RAD52. The antagonist effects of their deletion on HR frequency and their different modes of action (direct or indirect) to affect HR led us to choose these two genes to study the influence of their heterogeneous cellular amounts. This study provides evidence that cell-to-cell expression fluctuations of Rad27 and Rad52 produce heterogeneity in both spontaneous and induced $\mathrm{HR}$ frequency in the population. Moreover HR rate non-linearly scales with $\operatorname{Rad} 27$ levels. The recombination rate varies strongly above the mean Rad27 expression level of the population before reaching a plateau at its highest values for the highest expression levels. Finally, it does not result from differences in cell cycle distribution, and can be hardly explained by heterogeneity in DNA damage because it occurs also when cells are simultaneously sorted at equal level of the Bmh1 protein that is upregulated by DNA damage. Altogether, these results showed that noise in the expression of genes involved in DNA transactions can lead to heterogeneous HR rate between individual eukaryotic cells.

\section{MATERIALS AND METHODS}

\section{Yeast Strains and Growth Conditions}

All the strains and primers used in this work are listed in Supplementary Tables 2, 3, respectively. The strain KV133

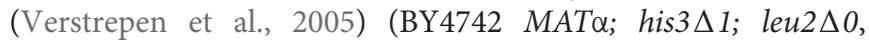
lys $2 \Delta 0$; ura3 $\Delta 0$ FLO1::URA3) (URA3 inserted in the middle of the tandem repeats) was kindly provided by Kevin J. Verstrepen (KU Leuven). To create strain JA0200 from KV133, a PCR fragment containing LEU2 and its native promoter and terminator was amplified from the genomic DNA of the S288c strain with primers $\mathrm{F} 1$ and $\mathrm{R} 1$, and transformed into KV133. The construction was verified by PCR with primers $\mathrm{C} 1$ and $\mathrm{C} 2$. To create the strains containing the fusion
RAD27-YFP and RAD52-YFP (JA0219 and JA0220, respectively), PCR fragments containing YFP-kanR and homologies to RAD27 or $R A D 52$ were amplified with primers $\mathrm{F} 2$ and $\mathrm{R} 2$, or primers F3 and R3, respectively, from the plasmid pfa6a-YFP-kanR (constructed in our lab), and transformed into JA0200. The constructions were verified by PCR with primers C3 and C4, or $\mathrm{C} 5$ and $\mathrm{C} 4$, respectively. To create the strains containing the double fusion RAD27-YFP-tdTomato and RAD52-YFP-tdTomato (JA0240 and JA0241, respectively), PCR fragments containing tdTomato-SpHis5 and homologies to YFP were amplified with primers F4 and R4 from the plasmid pfa6a-link-tdTomato-SpHis5 (Addgene), and transformed into JA0219 and JA0220. The constructions were verified by PCR with primers C3 and C6, or C5 and C6, respectively. To delete RAD27 (strain JA0217), a PCR fragment containing LYS2 and homologies to RAD27 was amplified from the genomic DNA of the S288c strain with primers F6 and R6, and transformed into JA0200. The construction was verified by PCR with primers C7 and C8. To insert $p B M H 1-y E G F P$ into the strains JA0240 and JA0200 (strains JA0242 and JA0243, respectively), the integrative plasmid pJRL2- $p B M H 1-y E G F P$ containing homologies to LEU2 was cut by AscI (New England Biolabs) and transformed. The construction was verified by PCR with primers C9 and C2. All the transformations were carried out by the standard lithium acetate method.

All the strains were grown in liquid YNB medium $[20 \mathrm{~g} / \mathrm{L}$ glucose (Sigma), $1.71 \mathrm{~g} \mathrm{~L}^{-1}$ yeast nitrogen base without amino acids and nitrogen (Euromedex) and $5 \mathrm{~g} \mathrm{~L}^{-1}$ ammonium sulfate (Sigma)] at $30^{\circ} \mathrm{C}$ with rigorous shaking $(200 \mathrm{rpm})$. Auxotrophic strains were supplemented with the required molecules at the following concentrations: $0.02 \mathrm{~g} \mathrm{~L}^{-1}$ histidine (Sigma), $0.05 \mathrm{~g} \mathrm{~L}^{-1}$ lysine (Sigma) and $0.1 \mathrm{~g} \mathrm{~L}^{-1}$ leucine (Sigma). For experiments of induction by phleomycin of the BMH1 promoter fused to GFP, cells in stationary phase were diluted 100 times in YNB medium containing $20 \mu \mathrm{g} \mathrm{mL}^{-1}$ phleomycin (Sigma), grown at $30^{\circ} \mathrm{C}$ with rigorous shaking $(200 \mathrm{rpm})$ and the fluorescence was measured after $0,2,4,6$, and $7.5 \mathrm{~h}$ for time-dependent induction; or in YNB medium containing 0,5 , 10 or $20 \mu \mathrm{g} \mathrm{mL}^{-1}$ phleomycin (Sigma), grown at $30^{\circ} \mathrm{C}$ with rigorous shaking $(200 \mathrm{rpm})$ and the fluorescence was measured after $6 \mathrm{~h}$ for dose-dependent induction. For recombination analysis after phleomycin treatment, cells in stationary phase were diluted 100 times in YNB medium containing $5 \mu \mathrm{g} \mathrm{mL}^{-1}$ phleomycin (Sigma) and grown at $30^{\circ} \mathrm{C}$ with rigorous shaking (200 rpm) for $16 \mathrm{~h}$.

The YPD plates contained $20 \mathrm{~g} \mathrm{~L}^{-1}$ glucose, $20 \mathrm{~g} \mathrm{~L}^{-1}$ agar (Euromedex), $10 \mathrm{~g} \mathrm{~L}^{-1}$ peptone (Euromedex) and $10 \mathrm{~g} \mathrm{~L}^{-1}$ yeast extraction (Euromedex). The 5-FOA and CAN plates contained $20 \mathrm{~g} \mathrm{~L}^{-1}$ glucose, $20 \mathrm{~g} \mathrm{~L}^{-1}$ agar, $1.71 \mathrm{~g} \mathrm{~L}^{-1}$ yeast nitrogen base, $5 \mathrm{~g} \mathrm{~L}^{-1}$ ammonium sulfate, $0.79 \mathrm{~g} \mathrm{~L}^{-1}$ complete supplement mixture (Euromedex) and $1 \mathrm{~g} \mathrm{~L}^{-1}$ 5-FOA (Euromedex) or $0.06 \mathrm{~g} \mathrm{~L}^{-1}$ canavanine (Sigma), respectively.

\section{Fluorescence Activated Cell Sorting}

The cell sorting experiments were carried out on the MoFlo Astrios EQ cell sorter with the Summit v6.3 software (Beckman Coulter). Cells in stationary phase were diluted 100 times and 
grown at $30^{\circ} \mathrm{C}$ with rigorous shaking $(200 \mathrm{rpm})$ for $16 \mathrm{~h}$ prior to cell sorting (final $\mathrm{OD} \approx 2$ ). Cultures were spun down at $3000 \mathrm{~g}$ for $5 \mathrm{~min}$ at $4^{\circ} \mathrm{C}$. Growth media was removed and cells were re-suspended in ice cold PBS. The SmartSampler and CyClone tubes holder were kept at $4^{\circ} \mathrm{C}$ during cell sorting. Cell sorting was carried out with $70 \mu \mathrm{m}$ nozzle and 60 psi operating pressure. The sorting speed was kept around 30,000 events per second. The purity mode for the sort mode and 1 drop for the droplet envelope were chosen. Based on the FSC-Area vs SSC-Area (488 nm laser) plot and the FSC-Height vs FSC-Area (488 nm laser) plot, single cells with similar cell size and granularity were first selected. Then based on the histogram of the YFP-tdTomato fluorescence (560 nm laser, 614/20 filter), single cells with $10 \%$ highest fluorescence and $10 \%$ lowest fluorescence were sorted simultaneously (Figure 2); or single cells were sorted simultaneously into five subpopulations distributed as follows: $0-10 \%$, median between the median of the $0-10 \%$ and the median of the whole population $\pm 5 \%$, median of the whole population $\pm 5 \%$, median between the median of the whole population and the median of the $90-100 \% \pm 5 \%, 90-100 \%$ (Figure 3). This division allowed reproducible sorting between replicates even if slight variations of the distribution of absolute expression levels occurred.

To sort GFP and YFP-tdTomato simultaneously, the fluorescence of the strains with only GFP (488 nm laser, 526/52 filter, strain JA0243) or YFP-tdTomato (560 nm laser, 614/20 filter, strain JA0240) was first measured. There is only negligible overlap between these fluorophores, hence there was no need for compensation. Then based on the GFP vs YFP-tdTomato plot of the strain JA0242, 5\% single cells of the total population with similar GFP fluorescence as the mean of the population but extreme YFP-tdTomato fluorescence were sorted, as well as 5\% single cells of the total population with similar YFP-tdTomato fluorescence as the mean of the population but extreme GFP fluorescence.

\section{Measurement of HR Frequency}

To measure the HR frequency of the whole population, $500 \mu \mathrm{L}$ culture $(\mathrm{OD} \approx 2$ ) was spread on 5 -FOA petri plates (100 $\mathrm{mm} \times 15 \mathrm{~mm}$, Fisherbrand). The culture was diluted 10,000 times and $20 \mu \mathrm{L}$ diluted culture was spread on YPD petri plates. The plates were kept in $30^{\circ} \mathrm{C}$ incubator for 3 days and the number of clones was counted. The size of the new FLO1 alleles from the clones isolated on the 5-FOA plates was analyzed by PCR using primers $\mathrm{F} 5$ and R5. The presence of URA3 was verified using primers $\mathrm{C} 10$ and $\mathrm{C} 11$. The size of FLO5 and FLO9 were further analyzed by primers $\mathrm{C} 13$ and $\mathrm{R} 5$ or $\mathrm{C} 12$ and R5, respectively. Then the frequency of loss of URA3 function was calculated as follow:

$$
f=\frac{n_{5-\mathrm{FOA}} \times 20}{n_{\mathrm{YPD}} \times 10000 \times 500}
$$

where $f$ denotes the frequency of loss of URA3 function, $n_{5-\mathrm{FOA}}$ denotes the number of clones on the 5 -FOA plates, and $n_{\mathrm{YPD}}$ denotes the number of clones on the YPD plates.

To measure the frequency of loss of URA3 function of the subpopulations, $5.10^{6}$ to $10^{7}$ cells (depending on the replicate) of each subpopulation were sorted (around $10 \mathrm{~mL}$ ) and spread on 5-FOA square culture dishes $(224 \mathrm{~mm} \times 224 \mathrm{~mm} \times 25 \mathrm{~mm}$, Corning). Then 100 cells were sorted and spread on YPD plates. The dishes were kept in $30^{\circ} \mathrm{C}$ incubator for 3 days and the number of clones was counted. The size of the new FLO1 alleles, the presence of URA3 or the size of the FLO5 and FLO9 alleles were analyzed by PCR from the clones isolated on the 5-FOA plates using primers F5 and R5, C13 and R5 or C12 and R5, respectively. Then the frequency of loss of URA3 function was calculated as follow:

$$
f=\frac{n_{5-\mathrm{FOA}} \times 100}{n_{\mathrm{YPD}} \times n_{\text {sorting }}}
$$

where $f$ denotes the frequency of loss of $U R A 3$ function, $n_{5-\mathrm{FOA}}$ denotes the number of clones on the 5 -FOA dishes, $n_{\text {YPD }}$ denotes the number of clones on the YPD plates, and $n_{\text {sorting }}$ denotes the number of cells sorted.

\section{Analysis of Cell Cycle Stage Distribution}

$10^{6}$ cells were sorted and fixed in $70 \%$ ethanol at $4^{\circ} \mathrm{C}$ for at least $12 \mathrm{~h}$. They were then washed in $50 \mathrm{mM}$ sodium citrate (Sigma) buffer ( $\mathrm{pH}$ 7.5) and treated by RNAse A (Eurogentec) and proteinase K (Eurogentec). Yo-Pro-I (Thermo Fisher Scientific) was used to stain the genomic DNA. The relative DNA content was measured by MACSQuant ${ }^{\circledR}$ VYB flow cytometry (Miltenyi Biotec).

\section{Statistics}

The Wilcoxon signed rank test was performed in $\mathrm{R}$ (version 3.4.1) with the wilcox.test function.

\section{RESULTS}

\section{Noise in the Expression of RAD52 and RAD27 Produces Heterogeneity in Spontaneous and Induced HR Rate}

The system developed by Verstrepen et al. to measure non-conservative $\mathrm{HR}$ between intragenic tandem repeats (Verstrepen et al., 2005) used the auxotrophic marker URA3 integrated in the tandem repeats of the FLO1 gene in S. cerevisiae (Figure 1A). As recombinants do not grow on the initial medium where URA3 is needed for growth because uracil is lacking (no clonal expansion possible), the frequency of yeast cells then growing on 5-FOA-containing medium provides a quantitative estimate of the actual recombination rates (number of events per cell division) as previously suggested (Verstrepen et al., 2005). However, the loss of URA3 function could also arise by direct mutations in the URA3 coding region.

This system confirmed that the absence of RAD27 and RAD52, respectively strongly increases and decreases the HR frequency (Verstrepen et al., 2005). The increased recombination frequency in $\operatorname{rad} 27 \Delta$ mutants suggests that FLO1 repeat instability is associated with the occurrence of DSB due to defective DNA replication (Kokoska et al., 1998). The absence of an effect in $\operatorname{rad} 51 \Delta$ mutants and the decrease in recombination observed in various other mutants, especially $\operatorname{rad} 50 \Delta$ and $\operatorname{rad} 52 \Delta$, suggests 


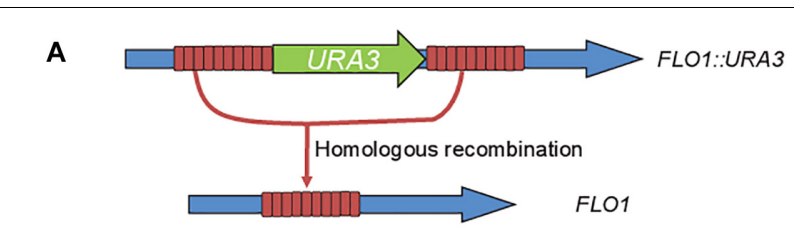

B
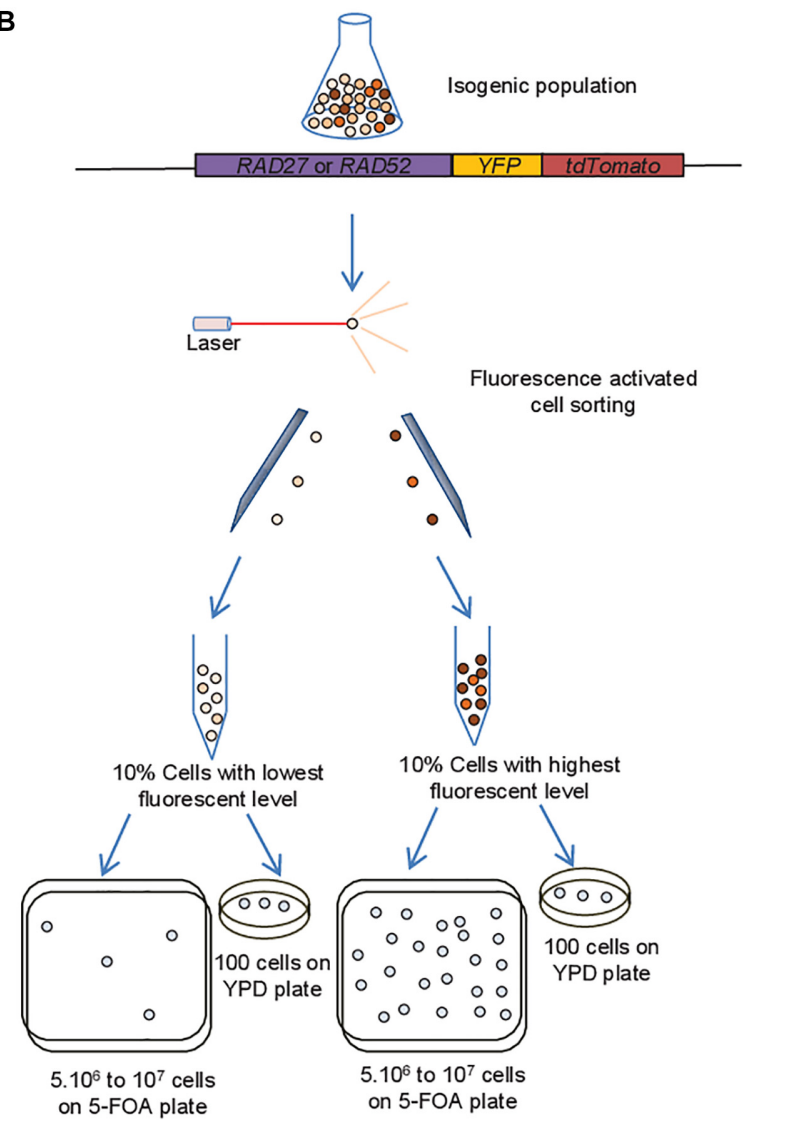

FIGURE 1 | Experimental procedure. (A) Homologous recombination (HR) frequency between intragenic repeats in FLO1 was measured by the loss of the URA3 expression cassette integrated in the middle of the FLO1 repeats (Verstrepen et al., 2005). When a recombination event occurs in the repeats, the URA3 marker loss results in a 5-FOA resistant (Ura-) strain containing a new FLO1 allele. (B) The double fluorescent marker YFP-tdTomato was fused to either RAD52 or RAD27 at their original genomic locus in the strain harboring the recombination substrate, allowing sorting of cells with extreme expression levels. $5.10^{6}$ to $10^{7}$ cells were sorted for each subpopulation, and spread on 5-FOA plates. In parallel viability was evaluated on YPD plates, allowing calculation their respective rate of loss of URA3 function.

that recombination in this system does not require strand invasion and depends on DSB repair by SSA (Verstrepen et al., 2005). Nevertheless, one cannot exclude that loss of URA3 could happen preferentially through gene conversion-associated crossing over in wild-type cells and that repair could switch to SSA in $\operatorname{rad} 51 \Delta$ mutants.

Subpopulations were sorted based on the expression level of RAD52 or RAD27 fused to YFP and tdTomato at their original genomic locus (Figure 1B). A fluorescent signal above the auto-fluorescence level for the whole population was needed to efficiently sort even the cells expressing RAD52 and RAD27 at the lowest levels. Thus, we chose tdTomato which is one the brightest fluorescence protein to be fused to $\operatorname{Rad} 52$ and $\operatorname{Rad} 27$ because of the low expression of the corresponding genes, and added YFP that improved the fluorescence of our tagged proteins compared to tdTomato only. This YFP-tdTomato double fusion to the C-terminal domain of Rad52 seems not to affect its functionality because the average HR frequency in the population was the same as in the wild-type (Supplementary Figure 1). On the contrary the Rad27-YFP-tdTomato fusion slightly decreased this average HR frequency (Supplementary Figure 1). Nevertheless the functionality of the fused Rad27-YFP-tdTomato protein is close to the native protein because it confers an HR rate that is in the same order of magnitude as the wild-type when compared to the strongly increased $\mathrm{HR}$ frequency in $\operatorname{rad} 27 \Delta$ mutants (Supplementary Figure 1).

Among the heterogeneous expression levels of these genes at the single-cell level, we first isolated the two extreme subpopulations in terms of fluorescence intensity, each of them representing $10 \%$ of the whole population. While viability was similar for both subpopulations (Supplementary Figure 2), the rate of loss of URA3 function as determined by the frequency of cells growing on 5-FOA plates (Figure 1B) was 10-times higher for the Rad27-high subpopulation (Figure 2A and Supplementary Table 1) and 4-times higher for the Rad52-high subpopulation (Figure 2B and Supplementary Table 1) compared to the low-subpopulations.

PCR amplification of the new FLO1 alleles in 5-FOA resistant clones showed that FLO1 is modified in the Rad27-high and Rad52-high subpopulations, and not in the Rad27-low and Rad52-low subpopulations, suggesting that recombination events and rearrangements among tandem repeats indeed led to the loss of URA3 only in the formers (Figure 2D and Supplementary Figure 3). As 5-FOA resistance can also arise through mutations in the URA3 coding region, we wanted to actually confirm the nature of the genetic changes by testing the presence of the URA3 gene in the resistant clones. We confirmed that the loss of URA3 gene in the Rad27-high and Rad52-high subpopulations occurred by recombination between intragenic repeats in FLO1 (Figure 2D and Supplementary Figure 3). The variability of the size of the new FLO1 alleles seen in Supplementary Figure 3 shows that these clones likely occurred during independent events and that they were not the result of clonal expansion. On the contrary, 5-FOA resistant clones from the Rad27-low and Rad52-low subpopulations still contained the $U R A 3$ gene at the expected size, showing that they likely acquired 5 -FOA resistance by mutation (Figure 2D and Supplementary Figure 3). Thus, the precise difference in HR rate between these extreme subpopulations cannot be quantified because of the absence of detectable recombinant cells in the subpopulations with the lowest expression levels.

The finding that Rad52-high cells harbor higher HR rate is in accordance with its direct involvement in HR pathways. In contrast, it could be at first glance counterintuitive to find Rad27-high cells with the highest $\mathrm{HR}$ rate considering that the deletion of this gene leads to increased recombination. Nevertheless Rad27 overexpression seems also lead to replication 

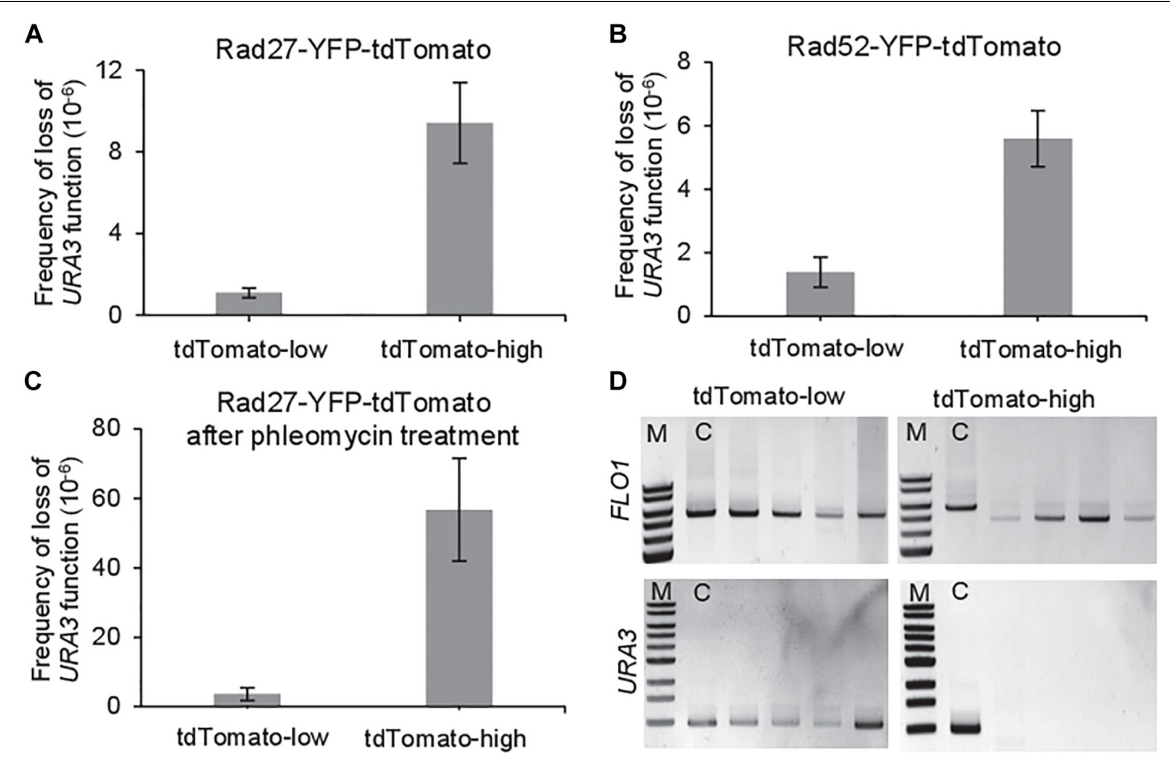

FIGURE 2 | Noise in the expression of genes affecting HR activity produces cell-to-cell heterogeneity in spontaneous HR rate. (A) Spontaneous frequency of loss of URA3 function in the subpopulations with the highest (10\%) and lowest (10\%) Rad27-YFP-tdTomato cellular amounts. (B) Spontaneous frequency of loss of URA3 function in the subpopulations with the highest (10\%) and lowest (10\%) Rad52-YFP-tdTomato cellular amounts. (C) Phleomycin-induced frequency of loss of URA3 function in the subpopulations with the highest (10\%) and lowest (10\%) Rad27-YFP-tdTomato cellular amounts. Results are the mean of three independent experiments with standard deviation. (D) Examples of PCR amplification of the new FLO1 alleles in 5-FOA resistant clones showing that their length is modified in the high-expressing subpopulations, and not in the low-expressing subpopulations compared to the control strain (C). PCR amplification of the URA3 gene in the same clones showed that it is lost by HR in the high-expressing subpopulations and still present in the low-expressing subpopulations.

stress and eventually DSBs that require HR for efficient repair (Becker et al., 2018), making the relationship between high Rad27 levels and increased HR rate not surprising.

To confirm the heterogeneity in spontaneous HR rate produced by the RAD27 heterogeneous expression levels, we induced the production of DSB by pretreating cells with $5 \mu \mathrm{g} \mathrm{ml}^{-1}$ phleomycin for $16 \mathrm{~h}$. This chemical is a water-soluble antibiotic of the bleomycin family that catalyzes DSB in DNA (Moore, 1988), thus strongly increasing recombination frequency. Sublethal concentration was used to avoid loss of cell viability in the subpopulations (Supplementary Figure 2) and to affect as little as possible growth (Liu et al., 2015), yet allowing measurable effect of the amount of induced DSB without toxicity. Frequency of loss of URA3 function is far more induced in the high-subpopulation than in the low-subpopulation following this pretreatment (Figure 2C and Supplementary Table 1). This stronger effect of the drug on the high level population is coherent with the fact that an increased level of Rad27 increases HR.

As it would appear difficult to reliably conclude the general effect of single-cell protein levels on recombination, we also assayed repeat expansion/contraction at other loci (FLO5 and FLO9) in these clones as previously performed among S. cerevisiae strains (Verstrepen et al., 2005). No variation was detected (Supplementary Figure 4) but the probability to observe HR events in both of these loci in the same cell during the course of our experiments is extremely low. Even on the whole sorted subpopulations; the rarity of such events makes their detection impossible without any selective pressure to enrich them. Nevertheless, testing integration of URA3 in other independent loci could draw a more general conclusion on the effect of protein levels on recombination.

\section{HR Rate Non-linearly Scales With Rad27 Levels}

Considering the high heterogeneity in HR activity observed between Rad27-high and Rad27-low subpopulations, we ask whether the HR rate scales linearly or non-linearly with $\operatorname{Rad} 27$ levels. To do so, we performed the same experiment as described in Figure 1B but we sorted cells into five subpopulations homogenously distributed in the population from the lowest (subpopulation 1) to the highest (subpopulation 5) expression levels (Figure 3A). Each subpopulation represents $10 \%$ of the whole population. The sorting process is less efficient when cells are sorted into five subpopulations instead of two. Far more time is needed to get the same number of cells in a given subpopulation when sorting into five subpopulations. Thus we were only able to sort out only around $2.10^{6}$ for each subpopulation which lasted at least $3 \mathrm{~h}$. Extending further the duration of the experiment would lead to bias linked to prolonged time in tubes before and after passage into the sorter, to the diluted medium in the harvest tubes ... Moreover inducing DSB was not chosen for this experiment because phleomycin treatment slightly increases the RAD27 expression level so that it does not allow studying basal expression level and spontaneous events that can be considered as more relevant to evolution. 

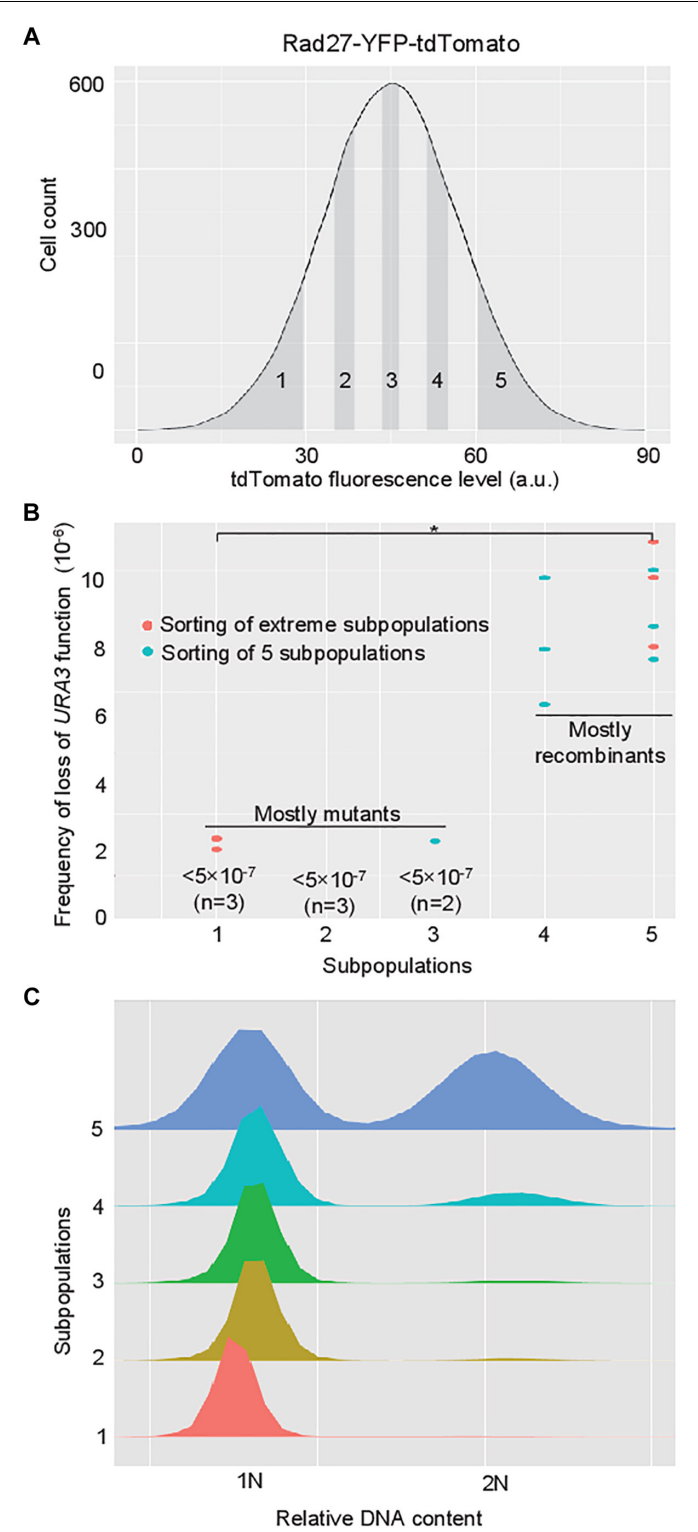

FIGURE 3 | HR rate non-linearly scales with Rad27 levels and is weakly correlated with differences in cell cycle distribution. (A) Five subpopulations homogenously distributed in the whole population were sorted thanks to the fused protein Rad27-YFP-tdTomato. Each subpopulation represents 10\% of the whole population. They are numbered 1-5 from the lowest to the highest expression levels. About $2.10^{6}$ cells were sorted for each subpopulation (three independent experiments), and spread on 5-FOA plates. In parallel viability was evaluated on YPD plates, allowing calculation their respective frequency of loss of URA3 function. Three independent experiments were performed. (B) Measurable rates on these five subpopulations (in blue) were combined to the results obtained in Figure $\mathbf{2 A}$ (in red) to plot the relationship between rate of loss of URA3 function and Rad27 levels. Each dot represents one sorting experiment for one subpopulation that has given a measurable rate. When no rate was measurable because of the absence of 5-FOA resistance clone, the maximal rate is written. As shown in Figure 2D, 5-FOA resistance is due to mutation-based inactivation of the URA3 gene in subpopulations $1-3$ and to recombination-based loss of the URA3 marker in subpopulations 4 and 5 . A significant statistical difference is represented by $\left({ }^{*}\right)$ when $p<0.05$ in Wilcoxon signed rank test. (C) Cell cycle distribution in the five subpopulations isolated from the Rad27-YFP-tdTomato-expressing population is represented.
By doing so, we did not detect any 5-FOA resistant cells in subpopulations 1 and 2 in any replicate (Supplementary Table 1). Only one clone was detected in subpopulation 3 in one experiment while many more and similar numbers of clones were observed in subpopulations 4 and 5 (Supplementary Table 1). We confirmed again that these resistant clones are generated by recombination when Rad27 levels are high. As results were similar for subpopulation 5 in both sets of experiments, we chose to combine the results on these five subpopulations with the results from Figure 2A to plot the relationship between the frequency of loss of URA3 function and $\operatorname{Rad} 27$ levels (Figure 3B). We indicated in this plot that resistance is mostly due to mutation-based inactivation of the URA3 gene in the first subpopulations and to recombination-based loss of the URA3 marker in subpopulations 4 and 5 . Thus, even we were not able to measure HR rate in the formers, it appears that HR rate non-linearly scales with Rad27 levels because it reaches a plateau in the latters after an abrupt variation that occurs at least between subpopulations 3 and 4 slightly above the mean expression level of the population.

Finally, we took advantage of having six independent replicates for high- and low-Rad27 subpopulations to perform a non-parametric statistical test. These data show a significant difference ( $p=0.03$; Figure 3B), suggesting that for other data where the same tendency is observed with only three replicates (high- vs low-Rad52, high- vs low-Rad27 with phleomycin), similar conclusions could be drawn (these data constitute too small data samples to robustly apply proper statistical analysis).

\section{Differences in Cell Cycle Distribution Do Not Explain Heterogeneous HR Rate}

Since cell-cycle dependence of transcription dominates noise in gene expression (Zopf et al., 2013) and that transcript level of RAD27 is not constant through the cell cycle (Skotheim et al., 2008), we determined whether the difference in recombination rate in the sorted subpopulations is not a consequence of different cell cycle states. We measured the cell cycle distribution among the same five sorted subpopulations. As the chosen sorting mode on the cytometer excluded most of the budding cells, strong enrichment in G1 cells was expected, that should limit the impact of cell cycle state or size differences. Indeed we observed almost exclusively G1 cells in subpopulations 1-3 (Figure 3C). Only subpopulation 5 contained more G2 cells, suggesting that a confounding correlation between high fluorescence and cell cycle position exists and that cell cycle could influence the recombination outcome. However, the strong increase seen between subpopulations 3 and 4 is associated to only a slight difference in cell cycle distribution with a small G2 bump. Moreover, if this appearance of G2 cells in subpopulation 4 was responsible for the strong increase in recombination frequency, we would expect an even higher increase in subpopulation 5 where G2 are far more abundant. Instead, subpopulation 5 with the highest expression levels harbored the same frequency of loss of URA3 function as subpopulation 4 in spite of its strong enrichment in G2 cells, 
making us thinking that cell cycle distribution only poorly influences recombination rate.

\section{Heterogeneity in HR Rate Does Not Result From Heterogeneity in DNA Damage}

Given the poor contribution of cell cycle and the unexpected correlation between the RAD27 expression level and HR rate, we went further in deciphering the origins of the heterogeneity in HR rate. Apart from cell cycle, heterogeneity in DNA damage could affect recombination activity. To study this hypothesis, we performed a double sorting of extreme subpopulations based on the expression of Rad27-YFP-tdTomato on one hand, and the expression of GFP driven by the promoter of the $B M H 1$ gene $(p B M H 1)$ on the other hand (Figures $4 \mathbf{A}, \mathbf{B}$ ). Bmh1 is one of the two yeast 14-3-3 proteins and many studies also showed the important role of 14-3-3 proteins in DNA duplication and DNA damage response in fungi (Kumar, 2017). Especially, it directly modulates DNA damage-dependent functions of Rad53 (Usui and Petrini, 2007) and it is upregulated by DNA damage along with other protein factors associated with DNA damage response (Kim et al., 2011). We verified the induction of $p B M H 1$ during induction of DNA damage by phleomycin. GFP expression is indeed induced in a time-dependent manner in $20 \mu \mathrm{M}$ phleomycin (Supplementary Figure 5A) and in a dose-dependent manner after $6 \mathrm{~h}$ of phleomycin treatment (Supplementary Figure 5B). Thus sorting cells with extreme levels of $\operatorname{Rad} 27$ and simultaneously at equal level of $p B M H 1$-driven GFP should ensure observing the phenomenon in cells with similar levels of DNA damage and showing that heterogeneity in DNA damage is not responsible for it. Moreover, it possesses a relatively strong promoter that allows GFP expression largely above the auto-fluorescence threshold.

Frequency of loss of URA3 function was again higher in Rad27-high than in Rad27-low cells when also sorting cells with the same GFP level (Figure 4C and Supplementary Table 1), with a 10-fold factor similar to the previous experiments (Figure 2A). No difference in viability was observed (Supplementary Figure 6). 5-FOA resistance was again due to recombination in Rad27-high sorted cells and to mutation in Rad27-low sorted cells, showing that the difference is due to differences in HR rate. On the contrary, both GFP-low and GFP-high subpopulations exhibited close frequency of loss of URA3 function when also sorted at equal level of $\operatorname{Rad} 27$. However, we noticed that 5-FOA resistant clones were slightly more frequent in GFP-low cells (Figure 4C). This higher HR rate might be explained by the fact that cells expressing $B M H 1$

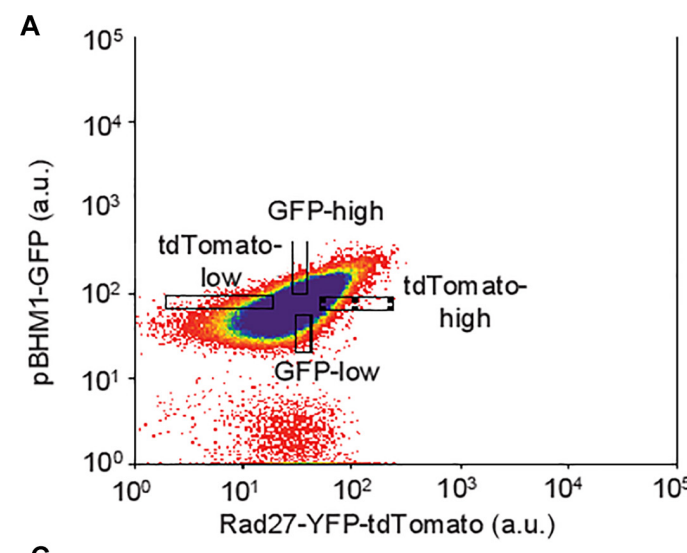

\begin{tabular}{|c|c|c|}
\hline Population & $\begin{array}{l}\text { YFP-tdTom ato } \\
\text { level (a.u.) }\end{array}$ & $\begin{array}{c}\text { GFP level } \\
\text { (a.u.) }\end{array}$ \\
\hline Total & 34.2 & 73.9 \\
\hline $\begin{array}{l}\text { tdTomato- } \\
\text { high }\end{array}$ & 57.9 & 77.2 \\
\hline $\begin{array}{l}\text { tdTomato- } \\
\text { low }\end{array}$ & 15.8 & 72.7 \\
\hline GFP-high & 35.3 & 108.5 \\
\hline GFP-low & 35.5 & 48.2 \\
\hline
\end{tabular}
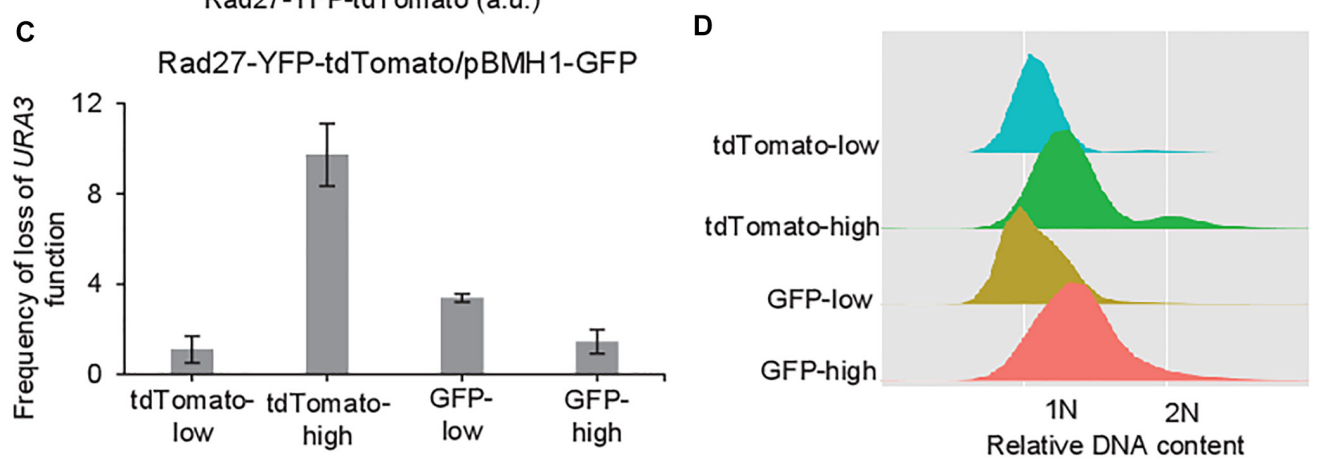

FIGURE 4 | The initiating DNA damage is not responsible for the observed heterogeneity in HR rate. (A) Dot plot of the population expressing pBMH1-GFP and RAD27-YFP-TdTomato, with gates allowing sorting of cells with similar expression levels of one fluorescent marker and extreme expression levels of the other. (B) Rad27-YFP-tdTomato and GFP levels in the four subpopulations isolated from the previous dot plot. (C) Spontaneous HR frequency in the subpopulations with similar PBMH1-GFP expression levels and the highest (10\%) and lowest (10\%) Rad27-YFP-tdTomato cellular amounts, and in the subpopulations with similar RAD27-YFP-TdTomato expression levels and the highest (10\%) and lowest (10\%) GFP cellular amounts. Results are the mean of three independent experiments with standard deviation. (D) Cell cycle distribution in the four subpopulations isolated from the previous dot plot. 
at lower levels might accumulate more DSB, which in turns could slightly enhance HR and/or mutation rate (Engels et al., 2011). Finally when analyzing cell cycle distribution, DNA content plot is shifted to the right for both high GFP and high tdTomato expressing cells (Figure 4D). If cell cycle distribution had a strong influence on recombination rate, both subpopulations would harbor increased frequency. Nevertheless a strong increase in the frequency of loss of URA3 function is only observed in tdTomato-high cells and not in GFP-high cells (it is even lower in the latter case). This argues again against its contribution in the generation of HR rate heterogeneity.

\section{DISCUSSION}

We observed heterogeneous HR rates in the subpopulations expressing RAD52 or RAD27 at the lowest vs highest levels, with the highest rates produced by the highest expression levels. Stochastic variations in Rad27 or Rad52 expression seem to be mainly responsible for variation in HR rate, but other sources of gene expression heterogeneity probably amplify this phenomenon at the whole-population scale. Especially, cell size effects could be considered and a recently developed strategy to account for cell size in using fluorescence as a gene expression proxy could be used to obtain a measure of fluorescence level independent of cell size (Duveau et al., 2018). However, we exclude that DNA damage heterogeneity is responsible for it because cells sorted at equal level of a DNA damage response protein (Bmh1) also harbored Rad27-dependent heterogeneity in HR rate. Moreover, viability is not more decreased by the phleomycin treatment in Rad27-high cells compared to the Rad27-low cells, suggesting that there is no more DNA damage that could explain higher expression in these cells. Finally, it is very unlikely that higher levels of $\operatorname{Rad} 52$ or $\operatorname{Rad} 27$ are in this state because of more underlying DNA damage that induces expression of HR genes rather than because of stochastic expression fluctuations. The contribution of cell cycle stage seems also weak because strong variations in HR rate between subpopulations are not correlated to strong changes in cell cycle stage, even if other experiments could confirm this point, for instance by blocking cells either in G1 or in G2, sorting them according to the expression level and measuring induced HR.

The correlation was somehow unexpected concerning RAD27 because $\operatorname{rad} 27 \Delta$ mutants showed increased $\mathrm{HR}$ in various studies (Johnson et al., 1995; Sommers et al., 1995). In fact, HR was found to be essential in rad27 $\Delta$ mutants (Symington, 1998). However, it was recently observed that overexpression of Rad27 makes yeast cells sensitive to hydroxyurea (HU), methyl methanesulfonate (MMS) and bleomycin (Duffy et al., 2016; Becker et al., 2018). Additionally, the study by Duffy et al. showed that the number of Rad52 spots increase when $\operatorname{rad} 27$ is overexpressed. The study by Becker et al. showed that Rad27 overexpression impedes replication fork progression and leads to an accumulation of cells in mid-S phase. Therefore it could be proposed that a high Rad27 level could generates DNA nicks or DSB that would induce an increase in HR frequency (Becker et al., 2018). Moreover previous results on chicken cells already suggested that $\operatorname{Rad} 27$ could facilitate HR by removing divergent sequences at DNA break ends (Kikuchi et al., 2005) making coherent the relationship we observed, even if it has also been shown as playing a role in limiting HR between short sequences in yeast (Negritto et al., 2001). Finally, it is worth noting that we tested phenotypic effects of gene expression noise providing limited quantitative variations from cell-to-cell unlike deletion experiments. Our results on Rad27 provide such example of molecular effects of weakly imbalanced protein levels that are the opposite of those resulting from simple deletion.

Apart from simple deletion (Yuen et al., 2007), expression variations of numerous genes are known to affect genome stability (Stirling et al., 2011; Ang et al., 2016; Duffy et al., 2016). As expected these genes are mainly involved in DNA damage response (e.g., DNA repair and recombination) and chromosome maintenance. In yeast, large scale screening revealed that many genes impact genome stability either when deleted (Yuen et al., 2007) or when differentially expressed (Stirling et al., 2011; Zhu et al., 2015; Duffy et al., 2016). Genetic events analyzed in these studies range from loss of a full mini-chromosome that measure chromosome instability (Yuen et al., 2007; Stirling et al., 2011; Zhu et al., 2015; Duffy et al., 2016) to loss of an endogenous locus (the mating type locus MAT on chromosome III for instance) that detect more limited genetic modifications (Yuen et al., 2007; Stirling et al., 2011; Duffy et al., 2016). These different types of measurements explain why genes impacting HR activity as RAD52 and RAD27 are not detected in the former case (Zhu et al., 2015), and observed in the latter (Yuen et al., 2007).

Two limitations can be highlighted about these works. First, genetic events resulting from multiple possible molecular mechanisms are detected, rendering impossible the quantitative analysis of a specific pathway in terms of event frequency. Loss of URA3 inserted among the FLO1 tandem repeats specifically detects limited deletions occurring between dispersed repeated DNA through SSA (Verstrepen et al., 2005), thus allowing this quantitative measurement of a specific pathway activity. Second, as mentioned in a recent study (Keren et al., 2016), these genome-wide libraries of knock-outs, reduction-of-function and overexpression delineate the effects of extreme expression levels that are typically far from wild-type expression: they do not reveal the dependence of phenotype on expression variations that occur in the vicinity of wild-type level. The authors of this study explored the relationship between gene expression and phenotype along a large expression spectrum with small increments to provide more information on the sensitivity of cellular properties to the expression levels. Unfortunately no gene involved in DNA repair or recombination was part of the study. A former study in E. coli modulated the expression of the mismatch repair protein MutL at multiple different cellular levels and revealed that the frequency of deletion-generating recombination is inversely related to the amount of MutL while mismatch repair activity is insensitive to fluctuations in MutL (Elez et al., 2007). Nevertheless in all cases phenotypic measurements were performed on whole populations harboring various mean expression levels, even if they were only slightly different. The present study takes a further step by allowing testing the degree of heterogeneity in genome stability in the 
range of "natural" or "physiological" stochastic variations of genes involved in DNA replication, repair and recombination.

$\mathrm{HR}$ can produce gene copy number variations (CNV) if the distance between the repeated sequences is relatively short (Hastings et al., 2009). Indeed, the fact that resection reaches both repeats so that the break is repaired by SSA is less likely when the distance separating the repeats increases (Hastings et al., 2009). More generally, SSA is responsible for repeat-mediated rearrangements (Bhargava et al., 2016) and HR globally contains the intrinsic capacity to modify genetic material through gene conversion and crossing over (Guirouilh-Barbat et al., 2014). Thus it was highly conceivable that noise in the expression of genes affecting HR activity produces variable capacity to evolve (evolvability; Capp, 2010), as recently suggested for mutagenesis in E. coli (Uphoff et al., 2016).

Interestingly from an evolutionary viewpoint, we observed that $\mathrm{HR}$ rate scales non-linearly with $\operatorname{Rad} 27$ levels. If the relationship was linear, the total amount of HR would depend only on the averaged $\operatorname{Rad} 27$ expression. On the contrary this non-linearity implies that mean doubling $\operatorname{Rad} 27$ levels do not lead to a doubling of HR rate. Total amount of HR cannot be explained solely by the population- or time-averaged $\operatorname{Rad} 27$ expression and slight modifications of the $\operatorname{Rad} 27$ mean expression level in the population could generate high variation in the total amount of HR and allow its rapid tuning without the need of strong expression variations or mutant alleles. Moreover, modifying $\operatorname{Rad} 27$ expression noise, while keeping the average expression level the same, would have an effect on the total amount of HR. Such modifications of noise levels have be considered as another way to modify HR rate at the whole-population level apart from modifications of mean levels. This also suggests that noise levels in the expression of genes affecting genome stability could be under positive or negative selection. This direct influence of gene expression noise on the rate of appearance of genetic variations has to be considered in addition to, and independently of, recent observations showing that evolvability is dependent on the level of noise in the expression of genes affecting resistance in selective environments because it shapes mutational effects (Bodi et al., 2017).

Finally the human RAD27 homolog FEN1 (Singh et al., 2008) and RAD52 (Lieberman et al., 2016), as well as many other genes involved in DNA replication, repair and recombination (Lahtz and Pfeifer, 2011; Chae et al., 2016), can be over- or under-expressed in human cancers thus producing genetic instability (Stratton et al., 2009). One can suggest that these expression variations are selected for along with the beneficial genetic alterations they have produced, the initial source of variations being gene expression noise (Capp, 2010). Moreover noise could be globally increased in cancer cells, with consequences on genome instability (Capp, 2005, 2010, 2017).

\section{REFERENCES}

Alexander, H. K., Mayer, S. I., and Bonhoeffer, S. (2017). Population heterogeneity in mutation rate increases the frequency of higher-order mutants and reduces long-term mutational load. Mol. Biol. Evol. 34, 419-436. doi: 10.1093/molbev/ msw244
Given the diverse influences of gene expression noise on genotype variations that this work and other recent works (Bodi et al., 2017) revealed, the idea to control the level of expression noise among cancer cells might allow limiting evolvability, and escape from therapy (Capp, 2012; Brock et al., 2015). The same idea could be applied to microbial populations in the aim to stabilize production phenotypes for instance by avoiding the appearance of extreme subpopulations with high genome instability that would more probably lose interesting production features. Finally, this interplay between the genetic, epigenetic, and gene expression variabilities is a highly exciting field of investigation, and could help elucidating the degree to which noise levels are indeed under selection and the environmental conditions favoring such selection (Keren et al., 2016), especially when affecting genome stability. In conclusion, the present study revealed that gene expression variability can produce heterogeneous evolvability through HR from cell-to-cell, with probable consequences for instance in terms of stress response in microbial populations or evolution of cancel cell populations in oncogenesis and therapeutic response.

\section{AUTHOR CONTRIBUTIONS}

JL, J-MF, and J-PC conceived and designed the experiments. JL performed the experiments. JL and J-PC wrote the manuscript.

\section{FUNDING}

This work was in part supported by the Agence Nationale de la Recherche (Grant No. ANR-12-JSV6-0006 to J-PC).

\section{ACKNOWLEDGMENTS}

We are grateful to Delphine Lestrade and Julien Cescut from the Toulouse White Biotechnology consortium for flow cytometry facilities, to Adilia Dagkesamanskaia and Catherine Botanch for her helpful contribution and to Sébastien Déjean for his advices on statistical analysis. We also thank Kevin J. Verstrepen for providing the KV133 strain containing the recombination substrate. Finally we are thankful to Fayza Daboussi, Yvan Canitrot, and Ivan Matic for critical reading of the manuscript.

\section{SUPPLEMENTARY MATERIAL}

The Supplementary Material for this article can be found online at: https://www.frontiersin.org/articles/10.3389/fgene. 2019.00475/full\#supplementary-material

Alvaro, D., Lisby, M., and Rothstein, R. (2007). Genome-wide analysis of Rad52 foci reveals diverse mechanisms impacting recombination. PLoS Genet. 3:e228. doi: 10.1371/journal.pgen.003 0228

Ang, J. S., Duffy, S., Segovia, R., Stirling, P. C., and Hieter, P. (2016). Dosage mutator genes in saccharomyces cerevisiae: a novel mutator mode-of-action 
of the Mph1 DNA helicase. Genetics 204, 975-986. doi: 10.1534/genetics.116. 192211

Balakrishnan, L., and Bambara, R. A. (2013). Flap endonuclease 1. Annu. Rev. Biochem. 82, 119-138. doi: 10.1146/annurev-biochem-072511-122603

Bar-Even, A., Paulsson, J., Maheshri, N., Carmi, M., O'shea, E., Pilpel, Y., et al. (2006). Noise in protein expression scales with natural protein abundance. Nat. Genet. 38, 636-643. doi: 10.1038/ng1807

Becker, J. R., Gallo, D., Leung, W., Croissant, T., Thu, Y. M., Nguyen, H. D., et al. (2018). Flap endonuclease overexpression drives genome instability and DNA damage hypersensitivity in a PCNA-dependent manner. Nucleic Acids Res. 46, 5634-5650. doi: 10.1093/nar/gky313

Bhargava, R., Onyango, D. O., and Stark, J. M. (2016). Regulation of single-strand annealing and its role in genome maintenance. Trends Genet. 32, 566-575. doi: 10.1016/j.tig.2016.06.007

Blake, W. J., Balazsi, G., Kohanski, M. A., Isaacs, F. J., Murphy, K. F., Kuang, Y., et al. (2006). Phenotypic consequences of promoter-mediated transcriptional noise. Mol. Cell 24, 853-865. doi: 10.1016/j.molcel.2006.11.003

Blake, W. J., KAErn, M., Cantor, C. R., and Collins, J. J. (2003). Noise in eukaryotic gene expression. Nature 422, 633-637. doi: 10.1038/nature01546

Bodi, Z., Farkas, Z., Nevozhay, D., Kalapis, D., Lazar, V., Csorgo, B., et al. (2017). Phenotypic heterogeneity promotes adaptive evolution. PLoS Biol. 15:e2000644. doi: 10.1371/journal.pbio.2000644

Brock, A., Krause, S., and Ingber, D. E. (2015). Control of cancer formation by intrinsic genetic noise and microenvironmental cues. Nat. Rev. Cancer 15, 499-509. doi: 10.1038/nrc3959

Capp, J. P. (2005). Stochastic gene expression, disruption of tissue averaging effects and cancer as a disease of development. Bioessays 27, 1277-1285. doi: 10.1002/ bies. 20326

Capp, J. P. (2010). Noise-driven heterogeneity in the rate of genetic-variant generation as a basis for evolvability. Genetics 185, 395-404. doi: 10.1534/ genetics.110.118190

Capp, J. P. (2012). Stochastic gene expression stabilization as a new therapeutic strategy for cancer. Bioessays 34, 170-173. doi: 10.1002/bies.201100149

Capp, J. P. (2017). Tissue disruption increases stochastic gene expression thus producing tumors: cancer initiation without driver mutation. Int. J. Cancer 140, 2408-2413. doi: 10.1002/ijc.30596

Chae, Y. K., Anker, J. F., Carneiro, B. A., Chandra, S., Kaplan, J., Kalyan, A., et al. (2016). Genomic landscape of DNA repair genes in cancer. Oncotarget 7, 23312-23321. doi: 10.18632/oncotarget.8196

Debrauwere, H., Loeillet, S., Lin, W., Lopes, J., and Nicolas, A. (2001). Links between replication and recombination in Saccharomyces cerevisiae: a hypersensitive requirement for homologous recombination in the absence of Rad27 activity. Proc. Natl. Acad. Sci. U.S.A. 98, 8263-8269. doi: 10.1073/pnas. 121075598

Dornfeld, K. J., and Livingston, D. M. (1992). Plasmid recombination in a rad52 mutant of Saccharomyces cerevisiae. Genetics 131, 261-276.

Duffy, S., Fam, H. K., Wang, Y. K., Styles, E. B., Kim, J. H., Ang, J. S., et al. (2016). Overexpression screens identify conserved dosage chromosome instability genes in yeast and human cancer. Proc. Natl. Acad. Sci. U.S.A. 113, 9967-9976. doi: $10.1073 /$ pnas.1611839113

Dumont, B. L., Broman, K. W., and Payseur, B. A. (2009). Variation in genomic recombination rates among heterogeneous stock mice. Genetics 182, 1345-1349. doi: 10.1534/genetics.109.105114

Duveau, F., Hodgins-Davis, A., Metzger, B. P., Yang, B., Tryban, S., Walker, E. A., et al. (2018). Fitness effects of altering gene expression noise in Saccharomyces cerevisiae. eLife 7:e37272. doi: 10.7554/eLife.37272

Elez, M., Radman, M., and Matic, I. (2007). The frequency and structure of recombinant products is determined by the cellular level of MutL. Proc. Natl. Acad. Sci. U.S.A. 104, 8935-8940. doi: 10.1073/pnas.0610149104

Engels, K., Giannattasio, M., Muzi-Falconi, M., Lopes, M., and Ferrari, S. (2011). 14-3-3 Proteins regulate exonuclease 1-dependent processing of stalled replication forks. PLoS Genet. 7:e1001367. doi: 10.1371/journal.pgen.1001367

Fraser, D., and Kaern, M. (2009). A chance at survival: gene expression noise and phenotypic diversification strategies. Mol. Microbiol. 71, 1333-1340. doi: $10.1111 /$ j.1365-2958.2009.06605.x

Guirouilh-Barbat, J., Lambert, S., Bertrand, P., and Lopez, B. S. (2014). Is homologous recombination really an error-free process? Front. Genet. 5:175. doi: $10.3389 /$ fgene. 2014.00175
Hastings, P. J., Lupski, J. R., Rosenberg, S. M., and Ira, G. (2009). Mechanisms of change in gene copy number. Nat. Rev. Genet. 10, 551-564. doi: 10.1038/ $\operatorname{nrg} 2593$

Hou, Y., Fan, W., Yan, L., Li, R., Lian, Y., Huang, J., et al. (2013). Genome analyses of single human oocytes. Cell 155, 1492-1506. doi: 10.1016/j.cell.2013.11.040

Johnson, R. E., Kovvali, G. K., Prakash, L., and Prakash, S. (1995). Requirement of the yeast RTH1 $5^{\prime}$ to $3^{\prime}$ exonuclease for the stability of simple repetitive DNA. Science 269, 238-240. doi: 10.1126/science.7618086

Kauppi, L., Jeffreys, A. J., and Keeney, S. (2004). Where the crossovers are: recombination distributions in mammals. Nat. Rev. Genet. 5, 413-424. doi: $10.1038 / \mathrm{nrg} 1346$

Keren, L., Hausser, J., Lotan-Pompan, M., Vainberg Slutskin, I., Alisar, H., Kaminski, S., et al. (2016). Massively parallel interrogation of the effects of gene expression levels on fitness. Cell 166, 1282-1294.e18. doi: 10.1016/j.cell.2016.07.024

Kikuchi, K., Taniguchi, Y., Hatanaka, A., Sonoda, E., Hochegger, H., Adachi, N., et al. (2005). Fen-1 facilitates homologous recombination by removing divergent sequences at DNA break ends. Mol. Cell. Biol. 25, 6948-6955. doi: $10.1128 / \mathrm{mcb} .25 .16 .6948-6955.2005$

Kim, D. R., Gidvani, R. D., Ingalls, B. P., Duncker, B. P., and Mcconkey, B. J. (2011). Differential chromatin proteomics of the MMS-induced DNA damage response in yeast. Proteome Sci. 9:62. doi: 10.1186/1477-5956-9-62

Kokoska, R. J., Stefanovic, L., Tran, H. T., Resnick, M. A., Gordenin, D. A., and Petes, T. D. (1998). Destabilization of yeast micro- and minisatellite DNA sequences by mutations affecting a nuclease involved in Okazaki fragment processing ( $\operatorname{rad} 27)$ and DNA polymerase delta (pol3-t). Mol. Cell Biol. 18, 2779-2788. doi: $10.1128 / \mathrm{mcb} .18 .5 .2779$

Kumar, R. (2017). An account of fungal 14-3-3 proteins. Eur. J. Cell Biol. 96, 206-217. doi: 10.1016/j.ejcb.2017.02.006

Lahtz, C., and Pfeifer, G. P. (2011). Epigenetic changes of DNA repair genes in cancer. J. Mol. Cell. Biol. 3, 51-58. doi: 10.1093/jmcb/mjq053

Lieberman, R., Xiong, D., James, M., Han, Y., Amos, C. I., Wang, L., et al. (2016). Functional characterization of RAD52 as a lung cancer susceptibility gene in the 12p13.33 locus. Mol. Carcinog. 55, 953-963. doi: 10.1002/mc.22334

Liu, J., Francois, J. M., and Capp, J. P. (2016). Use of noise in gene expression as an experimental parameter to test phenotypic effects. Yeast 33, 209-216. doi: 10.1002/yea.3152

Liu, J., Martin-Yken, H., Bigey, F., Dequin, S., Francois, J. M., and Capp, J. P. (2015). Natural yeast promoter variants reveal epistasis in the generation of transcriptional-mediated noise and its potential benefit in stressful conditions. Genome Biol. Evol. 7, 969-984. doi: 10.1093/gbe/evv047

Lu, S., Zong, C., Fan, W., Yang, M., Li, J., Chapman, A. R., et al. (2012). Probing meiotic recombination and aneuploidy of single sperm cells by whole-genome sequencing. Science 338, 1627-1630. doi: 10.1126/science.1229112

Moore, C. W. (1988). Internucleosomal cleavage and chromosomal degradation by bleomycin and phleomycin in yeast. Cancer Res. 48, 6837-6843.

Negritto, M. C., Qiu, J., Ratay, D. O., Shen, B., and Bailis, A. M. (2001). Novel function of Rad27 (FEN-1) in restricting short-sequence recombination. Mol. Cell Biol. 21, 2349-2358. doi: 10.1128/mcb.21.7.2349-2358.2001

New, J. H., Sugiyama, T., Zaitseva, E., and Kowalczykowski, S. C. (1998). Rad52 protein stimulates DNA strand exchange by Rad51 and replication protein A. Nature 391, 407-410. doi: 10.1038/34950

Newman, J. R., Ghaemmaghami, S., Ihmels, J., Breslow, D. K., Noble, M., Derisi, J. L., et al. (2006). Single-cell proteomic analysis of S. cerevisiae reveals the architecture of biological noise. Nature 441, 840-846. doi: 10.1038/nature04785

Paques, F., and Haber, J. E. (1999). Multiple pathways of recombination induced by double-strand breaks in Saccharomyces cerevisiae. Microbiol. Mol. Biol. Rev. 63, 349-404.

Raser, J. M., and O'Shea, E. K. (2005). Noise in gene expression: origins, consequences, and control. Science 309, 2010-2013. doi: 10.1126/science. 1105891

Rattray, A. J., and Symington, L. S. (1994). Use of a chromosomal inverted repeat to demonstrate that the RAD51 and RAD52 genes of Saccharomyces cerevisiae have different roles in mitotic recombination. Genetics 138, 587-595.

Silander, O. K., Nikolic, N., Zaslaver, A., Bren, A., Kikoin, I., Alon, U., et al. (2012). A genome-wide analysis of promoter-mediated phenotypic noise in Escherichia coli. PLoS Genet. 8:e1002443. doi: 10.1371/journal.pgen.100 2443 
Singh, P., Yang, M., Dai, H., Yu, D., Huang, Q., Tan, W., et al. (2008). Overexpression and hypomethylation of flap endonuclease 1 gene in breast and other cancers. Mol. Cancer Res. 6, 1710-1717. doi: 10.1158/1541-7786.MCR08-0269

Skotheim, J. M., Di Talia, S., Siggia, E. D., and Cross, F. R. (2008). Positive feedback of G1 cyclins ensures coherent cell cycle entry. Nature 454, 291-296. doi: $10.1038 /$ nature07118

Smith, M. C., Sumner, E. R., and Avery, S. V. (2007). Glutathione and Gts1p drive beneficial variability in the cadmium resistances of individual yeast cells. Mol. Microbiol. 66, 699-712. doi: 10.1111/j.1365-2958.2007.05951.x

Sommers, C. H., Miller, E. J., Dujon, B., Prakash, S., and Prakash, L. (1995). Conditional lethality of null mutations in RTH1 that encodes the yeast counterpart of a mammalian $5^{\prime}$ - to $3^{\prime}$-exonuclease required for lagging strand DNA synthesis in reconstituted systems. J. Biol. Chem. 270, 4193-4196. doi: $10.1074 /$ jbc.270.9.4193

Song, B., and Sung, P. (2000). Functional interactions among yeast Rad51 recombinase, Rad52 mediator, and replication protein A in DNA strand exchange. J. Biol. Chem. 275, 15895-15904. doi: 10.1074/jbc.m910244199

Stirling, P. C., Bloom, M. S., Solanki-Patil, T., Smith, S., Sipahimalani, P., Li, Z., et al. (2011). The complete spectrum of yeast chromosome instability genes identifies candidate CIN cancer genes and functional roles for ASTRA complex components. PLoS Genet. 7:e1002057. doi: 10.1371/journal.pgen.1002057

Stratton, M. R., Campbell, P. J., and Futreal, P. A. (2009). The cancer genome. Nature 458, 719-724.

Symington, L. S. (1998). Homologous recombination is required for the viability of rad27 mutants. Nucleic Acids Res. 26, 5589-5595. doi: 10.1093/nar/26.24.5589

Symington, L. S. (2002). Role of RAD52 epistasis group genes in homologous recombination and double-strand break repair. Microbiol. Mol. Biol. Rev. 66, 630-670. doi: 10.1128/mmbr.66.4.630-670.2002

Symington, L. S., Rothstein, R., and Lisby, M. (2014). Mechanisms and regulation of mitotic recombination in Saccharomyces cerevisiae. Genetics 198, 795-835. doi: 10.1534/genetics.114.166140

Thomas, B. J., and Rothstein, R. (1989). Elevated recombination rates in transcriptionally active DNA. Cell 56, 619-630. doi: 10.1016/0092-8674(89) 90584-9

Tishkoff, D. X., Filosi, N., Gaida, G. M., and Kolodner, R. D. (1997). A novel mutation avoidance mechanism dependent on $S$. cerevisiae RAD27 is distinct from DNA mismatch repair. Cell 88, 253-263. doi: 10.1016/s0092-8674(00) 81846-2
Uphoff, S., Lord, N. D., Okumus, B., Potvin-Trottier, L., Sherratt, D. J., and Paulsson, J. (2016). Stochastic activation of a DNA damage response causes cellto-cell mutation rate variation. Science 351, 1094-1097. doi: 10.1126/science. aac9786

Usui, T., and Petrini, J. H. (2007). The Saccharomyces cerevisiae 14-3-3 proteins Bmh1 and Bmh2 directly influence the DNA damage-dependent functions of Rad53. Proc. Natl. Acad. Sci. U.S.A. 104, 2797-2802. doi: 10.1073/pnas. 0611259104

Verstrepen, K. J., Jansen, A., Lewitter, F., and Fink, G. R. (2005). Intragenic tandem repeats generate functional variability. Nat. Genet. 37, 986-990. doi: 10.1038/ ng1618

Viney, M., and Reece, S. E. (2013). Adaptive noise. Proc. Biol. Sci. 280:20131104. doi: $10.1098 /$ rspb.2013.1104

Wang, J., Fan, H. C., Behr, B., and Quake, S. R. (2012). Genome-wide single-cell analysis of recombination activity and de novo mutation rates in human sperm. Cell 150, 402-412. doi: 10.1016/j.cell.2012.06.030

Yuen, K. W., Warren, C. D., Chen, O., Kwok, T., Hieter, P., and Spencer, F. A. (2007). Systematic genome instability screens in yeast and their potential relevance to cancer. Proc. Natl. Acad. Sci. U.S.A. 104, 3925-3930. doi: 10.1073/ pnas.0610642104

Zheng, L., and Shen, B. (2011). Okazaki fragment maturation: nucleases take centre stage. J. Mol. Cell Biol. 3, 23-30. doi: 10.1093/jmcb/mjq048

Zhu, J., Heinecke, D., Mulla, W. A., Bradford, W. D., Rubinstein, B., Box, A., et al. (2015). Single-cell based quantitative assay of chromosome transmission fidelity. G3 5, 1043-1056. doi: 10.1534/g3.115.017913

Zopf, C. J., Quinn, K., Zeidman, J., and Maheshri, N. (2013). Cell-cycle dependence of transcription dominates noise in gene expression. PLoS Comput. Biol. 9:e1003161. doi: 10.1371/journal.pcbi.1003161

Conflict of Interest Statement: The authors declare that the research was conducted in the absence of any commercial or financial relationships that could be construed as a potential conflict of interest.

Copyright (c) 2019 Liu, François and Capp. This is an open-access article distributed under the terms of the Creative Commons Attribution License (CC BY). The use, distribution or reproduction in other forums is permitted, provided the original author(s) and the copyright owner(s) are credited and that the original publication in this journal is cited, in accordance with accepted academic practice. No use, distribution or reproduction is permitted which does not comply with these terms. 